[DOI: 10.24214/jecet.A.9.4.62236.]

Juurnal of Enviranmental Science, Computer Science and Engineering \& Technology

An International Peer Review E-3 Journal of Sciences and Technology

Available online at www.jecet.org

Section A: Environmental Science

Research Article

\title{
Abusing and neglecting according to a child born accidentally raising sexuality by teenage parents' behaviors for looking for effective child care health conditions
}

\section{Jirawon Tanwattanakul ${ }^{1}$, Sriveing Pairojkul ${ }^{2}$, Peerasit Kamnuansilpa ${ }^{3}$, Wanapa Sritanyaratana $^{1} \&$ Toansakul Tony Santiboon ${ }^{4}$}

${ }^{1}$ Department of Child Health Nursing, Faculty of Nursing, Khon Kaen University, Khon Kaen, Thailand

${ }^{2}$ Karunruk Palliative Care Center, Srinagarind Hospital, Faculty of Medicine, Khon Kaen University, Khon Kaen, Thailand

${ }^{3}$ College of Local Administration, Khon Kaen University, Khon Kaen, Thailand

${ }^{1}$ Department of Child Health Nursing, Faculty of Nursing, Khon Kaen University, Khon Kaen, Thailand

${ }^{4}$ Research and Postgraduate Administrator at Curtin University of Technology, WA, Australia,

Received:10August 2020; Revised: 27August 2020; Accepted: 03 September 2020

\begin{abstract}
According to raising teenage parents though their abusing and neglecting children at a rural community with the ethnographic qualitative research method was surveyed. All children have protected on violence, abuse, neglect and exploitation from their teenage parents. To investigate and emphasize the consequences of violence ranged from immediate to the impact of their development on physical injury, learning ability, and local child care performance to long-term harm that caregivers carry into adult life is affected for raising children. Administration to the 89-households' families and household memberships, 10 house stakeholders, 8 community leaders, 36 children, 65 caregivers, teenage parents and grandparents, and 3 mentors. Using the ethnographic qualitative research participatory with observation,
\end{abstract}


natural conversation and in-depth interviews were randomized in rural Northeastern Region, Thailand. Most of the teenagers' education is poor learning skills, low academic learning achievements, and independent freedom of their sexual behaviors. These sexual intercourses between their groups are normal. Adding gambling habits among friends and adult groups are amputated without parents to dissuade. Either lifestyles as freely with sexually and gambling and the basic education are stopped, experiences' living skills are poorly. Teenage women are changed to pregnant and young mothers. The teenage men must be searched for the job without a lack of worker's skills to look for children with whom they are conflicted family relationships to take care.

Keywords: ethnographic qualitative research, the raising children, child abuse and neglecting, caregivers and grandparents, participatory observation, in-depth interviews, a local community, three forms of raising children and characterized raising children health

\section{INTRODUCTION}

The prevalence in South-East Asia was also high 33\% (1-5) for a given age is less than-2SD and is highly prevalent in developing countries especially among the poor and deprived segments of society [1]. The National Child Health Development Institute whereas serves as a health promotion system of Thailand with a mission consisting of developing, transferring knowledge, collaborating with use other partners as a learning and reference center for the promotion of newborn child health development - 5 years systematically and efficiently solving problems are provided ${ }^{[2]}$. The greatest increases in the complexity of social interaction were observed within stable friendship pairs, research suggested that there are distinctive characteristics of friendships, for infants, toddler, and pre-school aged children ${ }^{[3]}$.

Parents and caregivers who give attention, respond and interact with their child are literally building the child's brain to give them opportunities to explore their physical world and to provide safe, stable and nurturing environments ${ }^{[4]}$. Parenting is emotionally and intellectually draining, and it often requires professional sacrifice and serious financial hardship. Yet many of these same parents continue to insist that their children are an essential source of happiness, indeed that a life without children is a life unfulfilled ${ }^{[5]}$. Activities like a mommy-and-me music class or karate lessons can open their minds ${ }^{[6]}$ because they believe in always learning new skills are able to keep in mind that the grade is not what motivates a top child to succeed, it's his/her inner drive for learning ${ }^{[7]}$.

Parents can be punished for abusing their children, and failing to protect their children from abuse by others, or failing to curb their children's drug and alcohol abuse and participation in the crime. The legislation was passed partly in response to the rising juvenile crime and drug abuse rates ${ }^{[8]}$. The number of young children abandoned by parents to the care of grandparents has increased fivefold, especially in poor families in the Northeastern. According to a Thailand Development Research Institute; there are around 2.3 million households in which children are being raised by grandparents [9]. Thai family values have to make a decision either for or against their parents' wishes verses for against the wishes of their spouse, the family is more important than a job to their families, and having such strong family values make Thai's families much happier and more secure people ${ }^{[10]}$. Neglect a child at any place without arranging for appropriate safety protection or care; deliberately or neglectfully withhold from some child things that is necessary for sustaining the child's life or health, to an extent which seems likely to cause physical or mental harm to the child (Article 25) ${ }^{[11]}$. 


\section{MATERIALS AND METHODS}

The Child Development Center (CDC) in Thailand is supervised by 5 main Ministries, which is 5 coordinations; contribute to the development of quality child development centers ${ }^{[12]}$, these CDCs must be evaluated with the standard of the Office for National Education Standards and Quality Assessment to be used as a guideline for evaluating the performance of the center and as an instrument to improve the quality of the child center is assessed and education standards for early childhood education of educational institutions under the Local Government Organization, Ministry of Interior ${ }^{[13]}$, accounting the children population of Thailand as 11.36 million (boys as $5.81 \mathrm{M}$., girls as 5.55 M.) ${ }^{[14]}$ (Fig. 1).
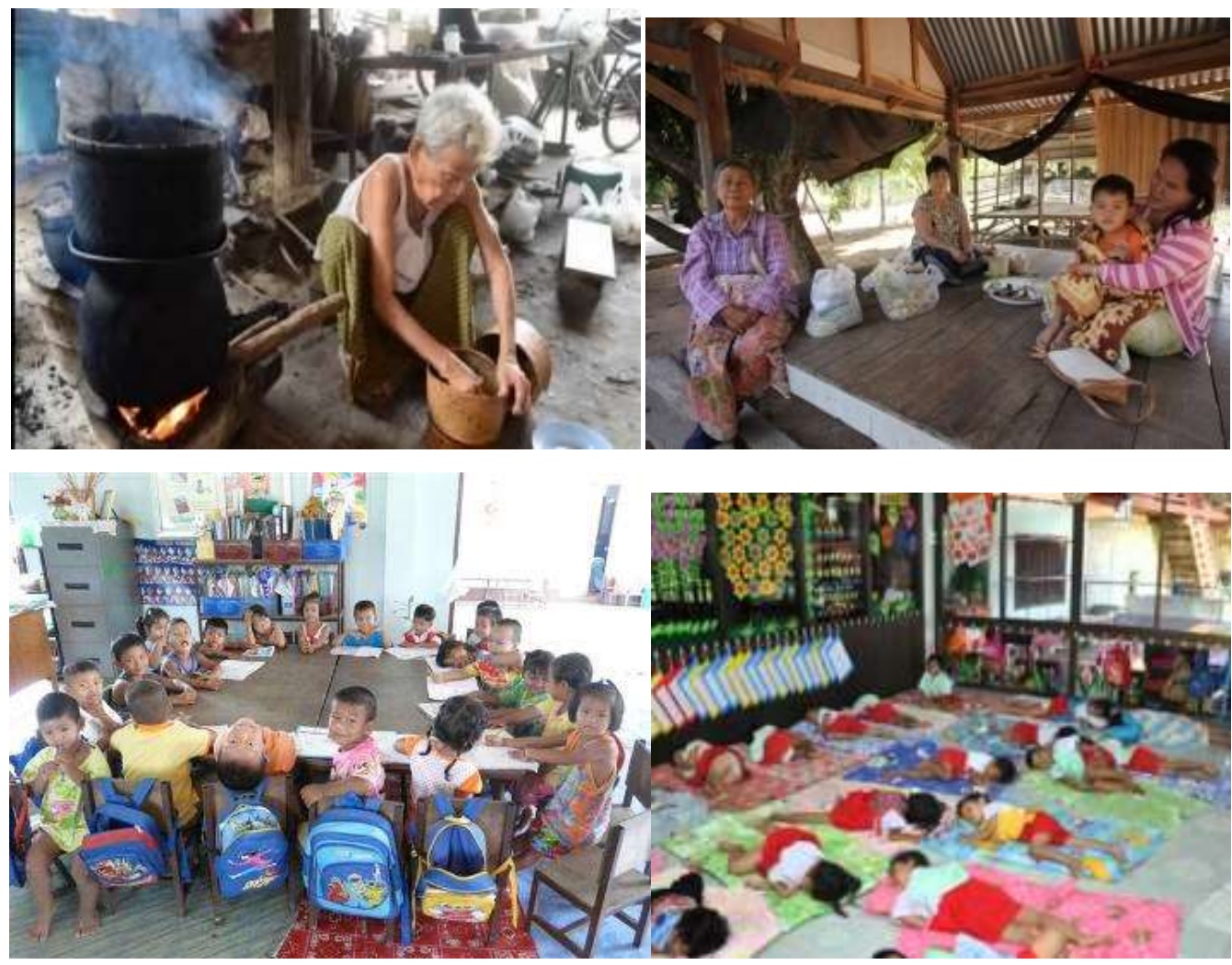

Fig. 1: Cultural lifestyle in Khon Kean, Northeastern Region, and the Child Center Development for Children (CCDC)

Parents recognize the increased pressure on adolescents to engage in risky behaviors such as substance use and delinquent behaviors. Parental monitoring includes tracking behaviors that regulate and provide awareness of a child's whereabouts, conduct, activities, and companions. Parenting style can either contribute to preventing adolescent risks such as substance use and delinquency. Authoritative parenting style, characterized by high levels of parental control, as well as high levels of warmth/responsiveness, protects adolescents against both substances use and delinquency as compared to adolescents raised in non-authoritative families. The Thai family culture contains much strength and these strengths may be retained even among families in urban Thai centers ${ }^{[14]}$ (Figure 2). 

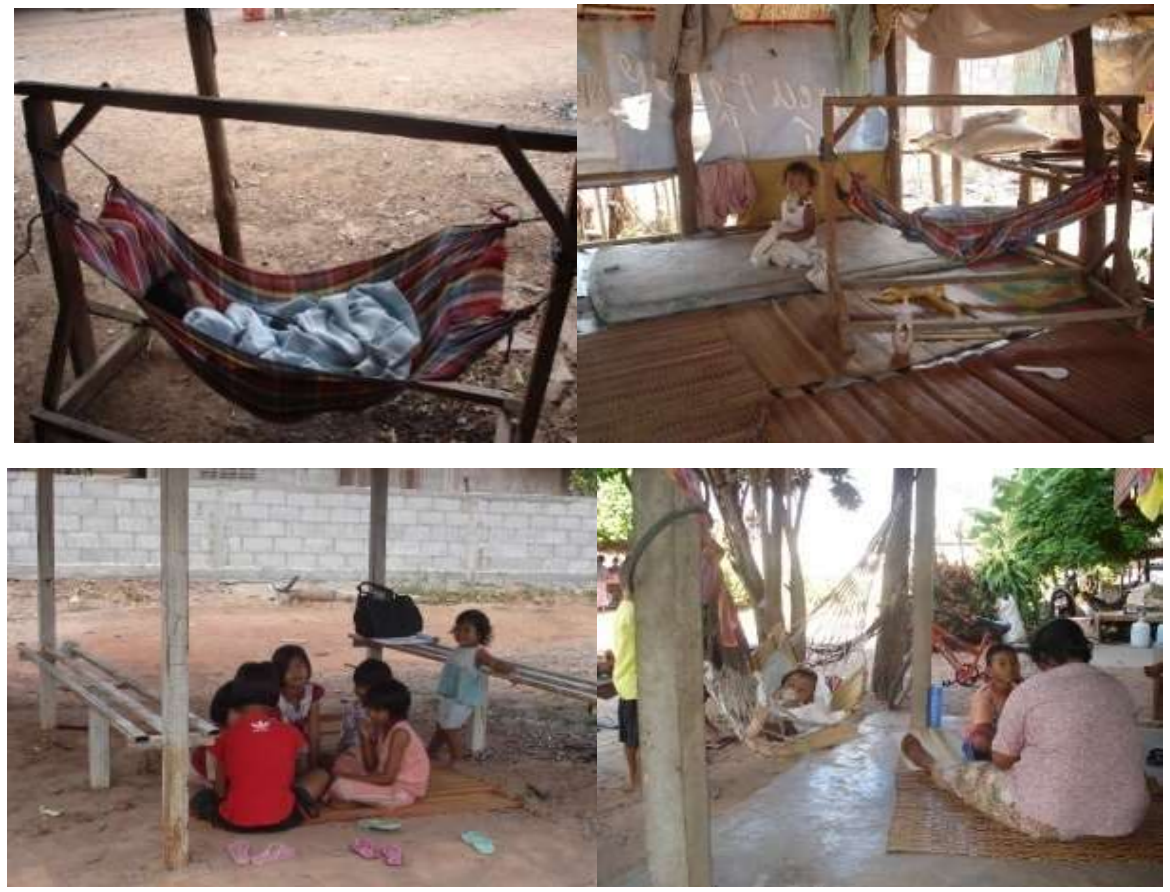

Fig. 2: The environmental child development centers' sampling and affecting a child abuse by grandmothers

Child abuse or child maltreatment is physical, sexual, or psychological maltreatment or neglect of a child or children, especially by a parent or another caregiver. Child abuse may include any act or failure to act by a parent or other the caregiver that result in actual or potential harm to a child and can occur in a child's home, or in the organizations, schools, or communities.Different jurisdictions have developed their own definitions of what constitutes child abuse for the purposes of removing children from their families to distinguish four types of child maltreatment: physical abuse; sexual abuse; emotional and psychological abuse; and neglect ${ }^{[15]}$.

All children have the right to be protected from violence, abuse, neglect, and exploitation, the consequences of violence range from the immediate impact on their development, such as physical injury, learning ability, and school performance to long-term the harm that they carry into adult life. In Thailand, there is an average of 52 children being sexual, physically or psychologically abused, neglected, or exploited each day or more than the 2-children in every hour ${ }^{[16] .}$

Neglected children are at risk of developing lifelong social, emotional and health problems, particularly if neglected before the age of two years. Child neglect is the failure of a parent or other the person with responsibility for the child, to provide needed food, clothing, shelter, medical care, or supervision to the degree that the child's health, safety or well-being may be threatened with harm. Neglect is also a lack of attention from the people surrounding a child, and the non-provision of the relevant and adequate necessities for the child's survival, which would be lacking in attention, love, and nurture ${ }^{[17]}$. Child neglect depends on how a child and society perceives the parents' behavior; it is not how parents believe they are behaving towards their child, parental failure to provide for a child [18].

Effects of the child neglect can differ depending on the individual and how much treatment is provided (Stone, 1998). Priorities for child protection in Thailand need to include community education, capacity building of child protection functionaries at all levels and in many forms so that 
all children receive the care they need and the community will be able to deliver quality services for children ${ }^{[19]}$.

In Thailand, population total as 67.4 million; life expectancy as 74.4 years; population ages $0-14$ years old as $19.2 \%$; and under-5 mortality rate as $11 \%$, with only $10 \%$ of the population living below the poverty line. They are neglected and afraid of rights, such as the right to education or the right to health. They are neglected and afraid of their family and friends ${ }^{[20] . ~ C h i l d r e n ~ o f ~ p o o r ~ f a m i l i e s ~ a r e ~ t h e ~}$ first victims when it comes to this issue. Many children are the victims of physical or sexual violence or abuse. Many of these cases are never reported as the children are afraid of reprisals and they still do not have access to the infrastructures to help them report this kind of violence [21]. There is a Child Protection Act 2013 with a team, the multidisciplinary and the center is just waiting to help but the problem persists under the community understand that have served in raising children or abuse and neglecting children with an emphasis on children under the age of 5 years, interestingly [21].

This study focused on the evidence for the effectiveness of intervention of this research project can be divided into five types: to investigate the ethnographic qualitative method, the research was to descript the raising children or abused and neglected children according to the views of the caregiver within a village, using a concept that reflects of their self-rearing children as children should receive for raising children (Figure 3).
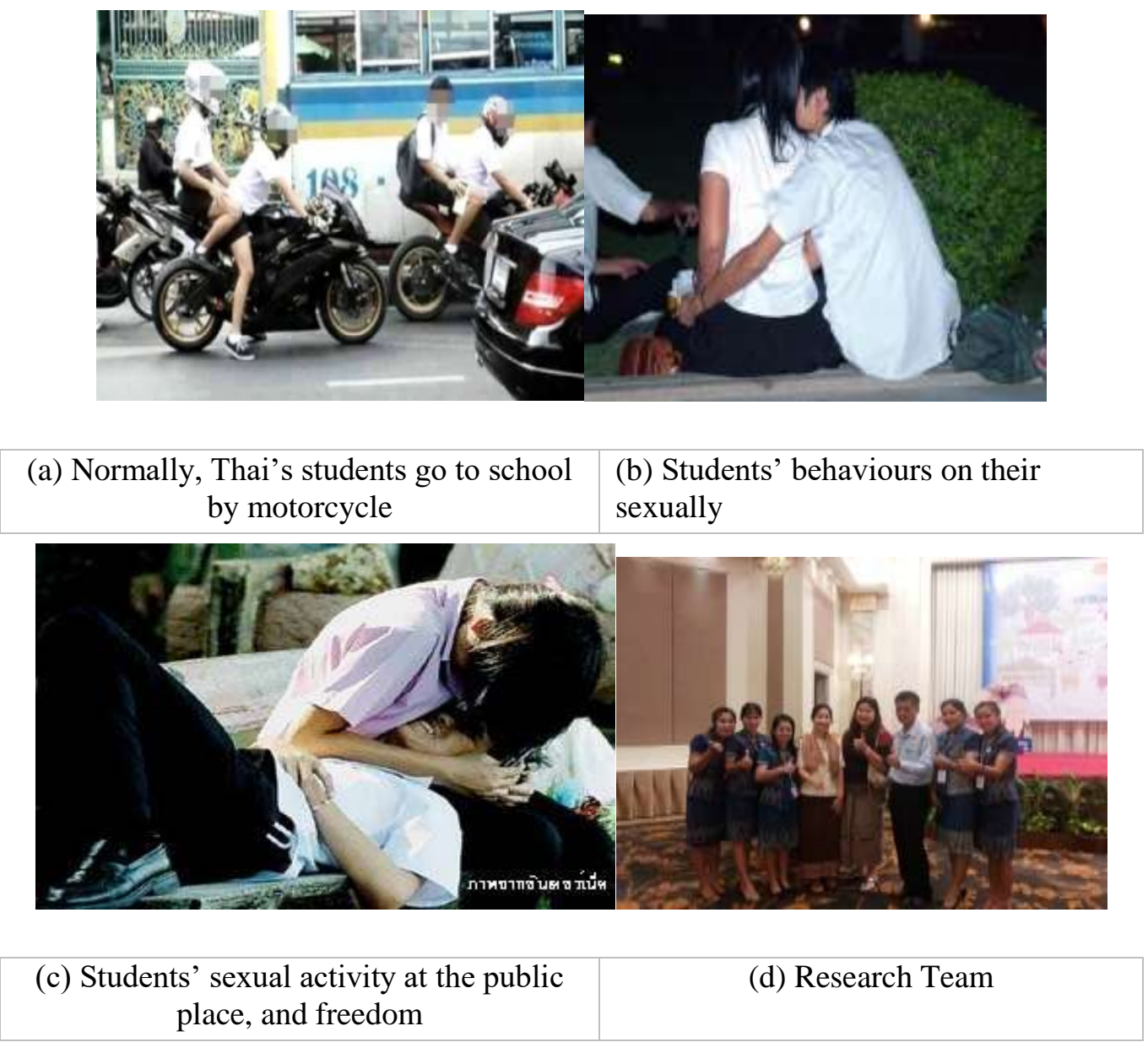

Fig 3: Research collections, limitations, and suggestions for this research project are provided 
To demonstrate a statistically significant was analyzed with the essence analysis, which can be attributed to the intervention to raise children or abuse and neglect children in the rural communities' target. The responding ethnographical data weren't realized or recognized that there is abuse and neglect of children by child caretakers, and using the qualitative studies which aim to illuminate the mechanisms through which this research project participant can access the resources and help offered in the this research project to achieve better outcomes.

Methods: The Act for Prevention and Solution of the Adolescent Pregnancy Problem 2016, which looks to reduce stigma on teen mothers, partially, young adolescents are generally less equipped than adults to make sound decisions and anticipate consequences of sexual behavior, although brain imaging and behavioral correlation studies in teens have been criticized for not being causative thus possibly reaffirming cultural biases. Using the ethnographic qualitative research method to investigate the affecting conditions of raising sexuality adolescence behaviours through teenage parents for their abusing and neglecting childhood health in this research study was modified.

Research objectives: To investigate the patterns of raising children at the child nurseries, the child development centers, or the Problem Child Care Centers in the government and private sectors were observed and associated.

Sample target group: Eighty-nine households from three sites representing three levels of development were analyzed in relation to family and household membership, as well as economic and employment status. In addition: A sample size target consisted of 24 families were collected. Focused on 36 children who were being aged under 5 years old with the purposive random sampling technique, the main informant was 65 caregivers who were parents and caregivers, and adding 10 house stakeholders, 8 community leaders, and 3 mentors with the participatory observation, natural conversation, and in-depth interviews were designed by the researcher through a Village in Nam Phong District local the community in Khon Kaen Provence, Northeastern Region of Thailand was selected (Figure 4).

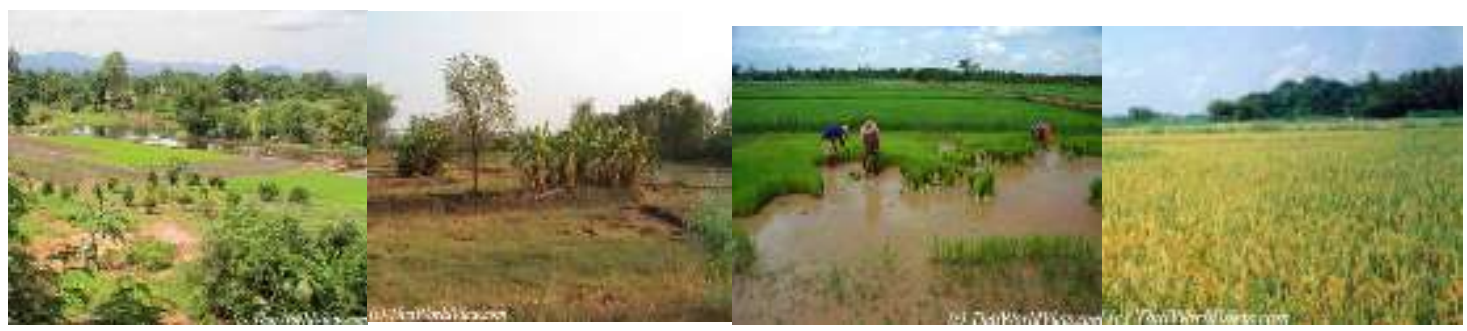

(a) Landscape of a Village sampling target

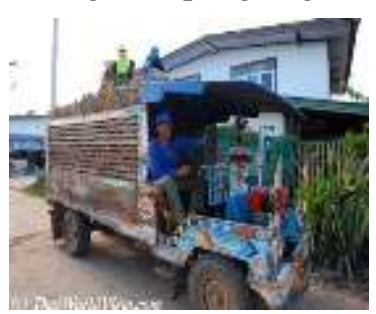

(e) Rice truck (b) Drought land

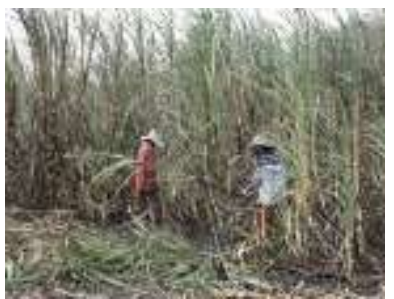

(f) Cane cutting profession (c) Rice field

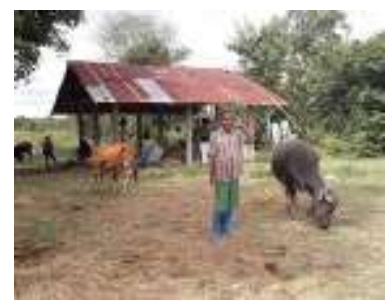

(g) Cow raising occupation (d) Golden rice field

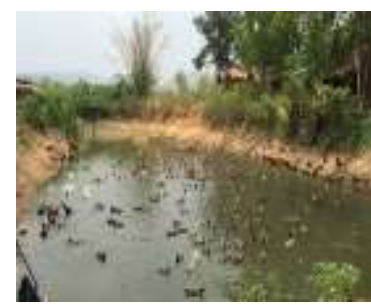

(h) Career raising chickens 


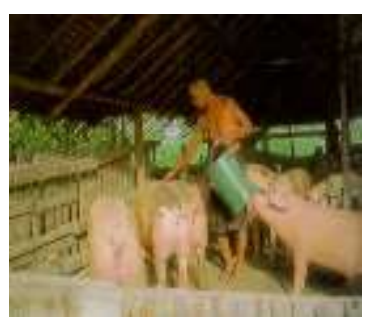

(i) Pork raising career

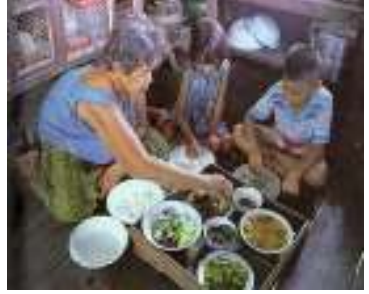

(j) Grandchildren \& grandparent

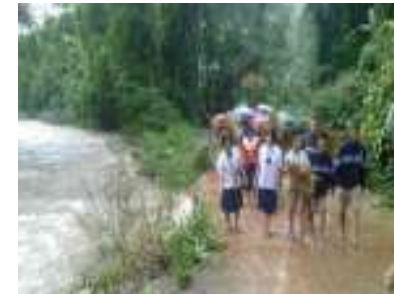

(k) Students go to their school in the rainy season

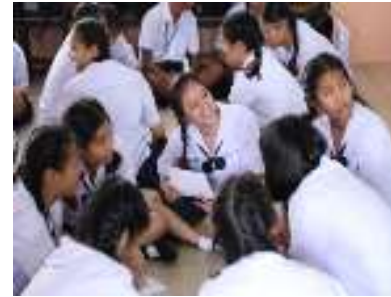

(1) Students' lifestyle

Fig. 4: Occupation adequacies of people at a local community, Nampong District, Khon Kaen Province

The cultural lifestyle of a rural community in Northeastern as ethnographic qualitative research:A rural area or countryside is a geographic area, Northeastern Thailand has been generally known is Thailand's poorest region. Agriculture is the largest sector of the economy. Farmers are increasingly diversifying into cash crops such as sugarcane and cassava, which are cultivated on a vast scale, and to a lesser extent, rubber. Silk production is an important cottage industry and contributes significantly to the economy. This village target is a large village divided into 2 village numbers. Living and lifestyle as the same house, the population of 1,303, and the number of houses are 28. Children under the age of 5 years old lived in a family that looks like these: 12 single families, 41 extended families and 6 families composed of grandparents and grandchildrenlived together. Both single-family and extended families, most of the caregivers are grandparents/grandparents. Parents are the secondary caregivers and assistants raising children (Figure 4).

Research Instruments: Because of the data, the collection is sensitive, telling their own life history as a father, mother, grandparent, grandmother, about child abuse to explain the connection connecting to children as the intergenerational transmission for a long time may use in-depth data collection techniques, the specific instruments to monitor and evaluate to the parents and caregivers within the organization that was more relevant to be collecting data on ethnographic quality the method was designed. Therefore, in this project research did not use the research instruments or tools were validated and reliable, significantly.

\section{RESULTS}

A sizable proportion of the adolescent population in Thailand, an adolescent has the right to make a decision by herself and has the right to information and knowledge, right to reproductive health service, right to confidentiality and privacy, and right to social welfare provision, that is equal and non-discriminative, and is entitled to any other rights for the purpose of this act accurately, completely, and adequately. However, the educational establishment shall undertake the prevention and solution of adolescent pregnancy problems

A local family's responses of her telling to her lifestyle and activities in daily life to the research team as followed:

"Wakes up at 4.00 am, I (father) will prepare a spade, goes out to the rice field is near this house, goes out in the morning to dig the clay to make the rice fields open, the farm is going to prepare the soil, the grass must go in the morning, after that will go out to eat at home. At the afternoon, goes out and grazes the grass for the cow, takes the cow to drink water, If it is rice farming season, prepare the soil, plant sugarcane, cut sugar cane, it will take time to work there all day." 
As for the housewives, the farmers worked to help the husband to be a housekeeper, take care of the children, and have a way of working in the morning as following:

"I am a housewife, will prepare food steamed sticky rice, makes food in the morning to complete, and prepare for the children and grandchildren. Children have breakfast before going to school, putting money for the children. In the afternoon, bring the cow to drink water. In the evening, preparing food to wait for catching my children, my grandchildren, and my husband who will come back at home. I have never buy rice because we have the own farming, growing many vegetables that they without toxins, fling the fish from in the swamp,chicken duck fed can be used as food for the family, immediately. In the evening, having dinner together with the whole family, children are acting themselves."

Most factories in the community will pay for travel expenses. Get wages more than working in a factory near the house, and then they send money back to their mothers (grandmother) to feed and look for their children (grandchildren).

.."Before I ( 40years old) used to work in a sugar factory, while my daughter has her children so that she took me to take care, my grandchildren are resigned from the job to raise a grandchild. Daughter and son-in-law went to work to earn money in the big cities."

"I am a mother, the birth of the first child of my age as 15years. At this time, I am 19years old. The first child is 4years old; the second child is 10days old. Initially, he intends to feed himself. I took the child to the mother-in-law instead, going to have a job with my husband in Bangkok. Finally, we are working in a neighborhood near the village and farming, and others in the inheritance that parents have given to my husbands."

In a village target, Young generation can apply for work, but it is not for elderly people (age over than 40-year-old). Mat weaving profession becomes the main occupation of the family. However, raising children will use more money according to the development of technological progress needs for living things in the village.

Finally, UNICEF ${ }^{[22]}$ Thailand's work on child protection focuses on strengthening the child protection system to prevent and respond to gender-based violence, abuse, neglect, and exploitation of children. This builds on efforts for law reform and enforcement, promotion of appropriate attitude on violence, development and strengthening of essential services and rehabilitation, and building capacity of family, community, and service providers, etc.

Education of children in the village: There is a place for supporting kindergarten; a Child Development Center (CDC) located in the village, aged 21/2 - 5years in the village. There are 4 mentors, 64children. Most people prefer to send their children to this center, paying a 50baht monthly maintenance fee. The opinions of local people talk about their children to the CDC are provided.

"It is able to go easy and convenient, take their children to study at the center in the morning and in the afternoon, they will go back."

But some people said that:

"I think that the mentors don't teach our children, only to eat and sleep. The reading, writing, and developing learning skills are unreadable. Unlike children who are taken to the private schools in the district; how long can learn, read, and write in a few times?"

Some caregivers will walk to send children as they said that: 
"I (56 years old) don't have enough money to pay for my children to go to school. I sent 4 grandchildren with a water cart on foot for walking on far away".

There is an Opportunity Extension School whereas is not far from the village, to manage the instruction from young children to lower secondary education (Grade 1 - 9). Most of the students are not good learning skills and low achievements; there are too many problems.

"Those who are in school here, it's good to learn but only drinks alcohol, take medicine, having sex between students together until pregnant and must be left out from the school."

"Schooling children fleeing school not dedicated to their own learning invited friends to dress up the car to drive between groups. When he was expelled from school at the grade $8^{\text {th }}$ level, he/she was angry with the teacher who was cut his hair until the head was cropped so that he did not go to school."

There is the first Secondary Educational School in this District whereas it is far from the village is 15 kilometers, which students in the village want to attend studying:

"If some children are going to enter to this school in the district, the shift is considered to have a high level of their learning ability." "Have the ability to take this school entrance examination; my grandchildren are not good at their learning skills and his parents didn't live with us."

Some people think that if their children are going to school in the district will have higher expenses, as in the example:

"Go to school in the district, the cost is high, my family is poor, school expenses are varied. I'm afraid that I won't have enough money to pay. Therefore, wishing to learn in a high school in the village, I'm afraid that if not letting him go to learning, my grandchildren would be sad. I don't know how to talk to my grandchildren as follow he will understand."

Sexual behavior of groups with their local community group: The ethnographic qualitative research data indicate that sexually active young people frequently engage in or are subjected to, risktaking behaviors that may expose them to sexually transmitted infections and unwanted pregnancies. The children who are young age, and also engage in unprotected sexual intercourse with various types of sexualized with their partners and young girls especially had often experienced sexual coercion between the young guys in this village together (Figure 6). For example:

Late today, the researcher went to scaffold and we found threegrandmothers who were sitting. One grandmother said:

"I was very upset, so sick and sick for my twograndchildren because after the daughter-in-law who had the second nephew was born for 9months and went to work in the factory. In a different place with the son, she went to have a new husband. The grandchildren were in a broken home". A grandparent said that "must be psychological abuse and I came up with will their mom take care of my grandchildren neglected or not? I cannot recognize it, pity but the children born to meet this condition." 

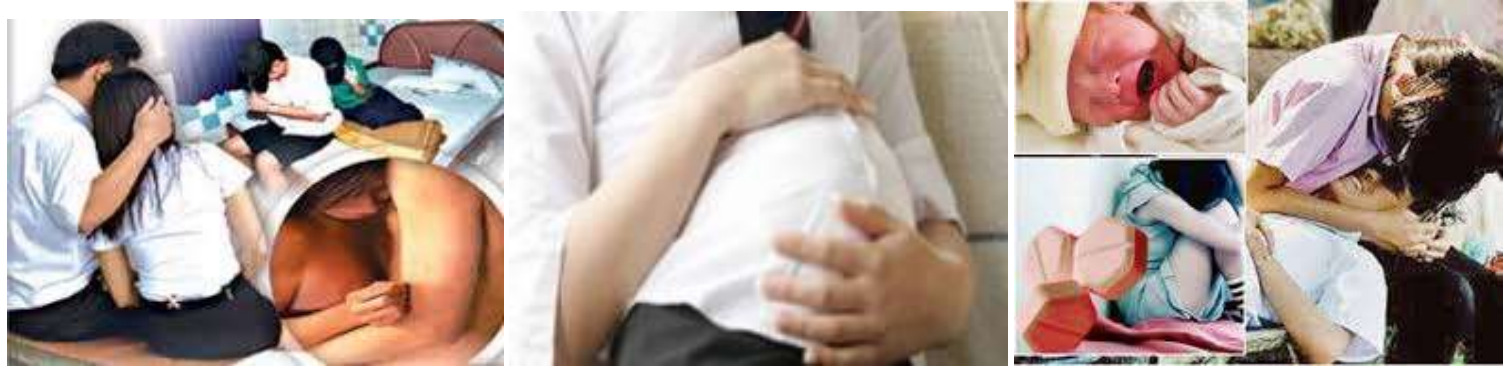

Fig. 5: Affecting conditions of raising sexuality adolescence behaviours through teenage parents for their abusing and neglecting childhood health

Sexual behavior of adolescents: Since adolescents are now engaging in sexual activity in their early years, sexual behavior needs to be explored to prevent contact. The factors contributing to low sexual risk behaviour was helping the family to do housework, and emphasis on learning, listening to parents, and following their advice. Adolescent behavior leading to high sexual risk included being very close to friends, having a wide social circle, going out for enjoyment at night time, returning home late at night, drinking alcohol, smoking, paying less attention to learning, not listening to parents, and not following their advice, for example:

"Adolescents in the village, both girls and boys, which was the age of studying at the secondary level and vocational level is the time when boy/girlfriends have started later, having sex with fellow students together", and for a child was born from their teenage parents who are in school-age until their pregnancy.

According to the observations of the researchers, the children started to have a girlfriend. The family did not say how, even though many men were fond of children, don't say how well later, when having sex in school age: "I don't know what to do children like it. What are they doing? When our daughter came to tell for the male parents to ask dowry will call fifty thousand."

From the case of teenagers having sex then unwanted pregnancy, the researcher noted that the parents and grandparents have accepted and will be able to deal with difficult situations. To be able to take care of grandchildren born from the inability to become a parent of a teenager is taken care of their new young born children to at least in five years. How to be raised depends on the caring of grandparents, especially, the grandmother who will be the primary caregiver before the children must be gone to the children development center in this village.

The lifestyle of people in the community gambling group: Focused on the village target community; there are 3 types of gambling people in this village community, such as:

Group 1; playing as a professional, playing regularly, playing all day, eating in a gambling band, they sometimes not going to sleep at home, plays across the day overnight. This group earns money by playing cards and playing dice.

Group 2: plays regularly, playing almost every day, play around noon after the housework is finished until $5 \mathrm{pm}$ and then go home to prepare dinner for the family. Most of they are housewives, and people who are unemployed and have a job but when there is free time.

Group 3: Children who play only during school holidays played during April-May, which during the big holidays. The players will be primary school students (grade 4-6), secondary school children (grade 7-12) to play as the Card or Hilo bands. 
On a day, the researcher went to sit at Mrs. Dee's house (19 years old, had 2 children). "My mother and father are money seekers to use by ourselves and my husband not working. Mother and father went to work in the provinces, and then they will return to be the dealer of Hi-Lo Gambling band every Saturday - Sunday, regularly. Mother will be arrested very often, lying in the jail for 1-2 nights. When losing money, then get out, don't be scared, say and laugh. "

Observations of the researcher about the situation of playing cards of children in the community that was very worried that he had absorbed and imitated adults. The cycle of gambling will continue in the community. Finally, some ethnographic qualitative data were to descript the raising children or abuse and neglecting children according to the views of the parents within a village with an in-depth interview as following:

"I am doubly troubled: there are two children (a girl, and a boy). My daughter had escaped from the house since the 7th grade to stay at a friend's house. The house has ten teenagers together. Mixed together both male and female. Parents will pick her up to come back home", she said "No. teenager female let men have sex to her, they sometimes switch between pairs. If they will return to their home according to the money runs out." "My son went to sleep with the girl at my home. Her parents went to inform the police. I must pay and lose money for him to set fifty thousand. When I say to him, he tells me that the young teenager wants to come with me and I am now all wasted."

Adolescent alcohol: Thai teenagers currently have more alcohol consumption habits. Especially in the younger age group, which the government has banned the sales of alcohol to children under 18 years old, the results of the research found that the scores of the alcohol consumption among teenagers who live in this village were higher increasingly. The researcher noted that there are many housewives groups, drinking so much that there is the appearance of alcohol addiction, trembling, drunk all the time. Some people are diagnosed with medicine. That is alcoholism (chronic alcoholism).

As above, raising children or abuse and neglecting childrenunder the description the lifestyles of people in the village, including the demographic characteristics and families of children in the community, occupation adequacy of expenses and money life education of children in villages, relatives, and neighbors sexual behaviors of the young mom and young dad lifestyles in the community are analyzed with the essence analysis method. Gambling group and belief in raising children and the lifestyle of children in order to make them understand the lifecycle of people in communities of various ages to the effects of the raised children, child abuse and neglecting children are destroyed more clearly. UNICEF aims to provide technical assistance to generate evidence to inform advocacy. Especially, children sexually in the local communities in Northeast Region in Thailand looks like normally.

\section{DISCUSSIONS}

This research project designed to help families where neglect is a concern that the principal factor influences parents' engagement and perception of the quality of the relationship that they are able to build up with the practitioner delivering and helping practitioners engage parents into the intervention. Giving family members time to talk about their problems both during and out of appointments are supported. Advocating for the family on issues with which the intervention is not directly concerned. Ensuring that fun forms a part of the interaction. Making family members feel cared for through the provision of clothes, food, and gifts. Giving parents a lead in analyzing the ethnographic qualitative family functioning and parenting are integrated. In this case; grandparents are asked about their 
experience of the intervention, parents invariably referred to the care and support provided by the practitioner. Effectively the intervention is experienced as an aspect of the overall relationships to improve the raising, abusing, and neglecting the protection of the children whose age less than 5 years old in a village and all of the villages throughout Thailand. Children of abusive and neglectful parents commit violence in the future ${ }^{[23]}$. The attachment style of children of abusive parents was less secure compared to children with authoritative caregivers. There are three parenting styles that lead to child neglect: authoritarian, permissive, and disengaged styles ${ }^{[24] .}$

There are a variety of ways in which children can act in response to an experience of the neglect. Some children attempt to talk about their neglect with their parents. Some children steal money from their parents' purses in order to feed themselves. Babies are too young to ameliorate parental neglect. However, in some cases of siblings will step in and take care of them. Some older siblings go without food so that their younger siblings can eat. Children sometimes also sexually, physically, and emotionally abused by their friends that they with disabilities were vulnerable to child abuse in their schools. Child abuse is an international phenomenon. Poverty and substance abuse are common social problems worldwide, and no matter the location, show a similar trend in the correlation to child abuse [25].

\section{CONCLUSIONS}

To investigate the ethnographic qualitative research was to descript the raising children or abuse and neglecting children according to the view of the caregiver within a village in Thailand. Administration to the sample size consisted of 24 families, 36 early childhoods, 65 caregivers, 10 house stakeholders, 8 community leaders, and 3 mentors were selected with the participatory observation, natural conversation, and in-depth interviews were designed by the researcher. The responding ethnographical data weren't realized or recognized that there are abuse and neglect of children by child caretakers. But there was a concept that reflects their self-rearing children as children should receive for raising children.

Childcare providers in the community have raised children in 3 forms included:

The first pattern: "Is the house is the city", the moderator views of their self-care for children liked people in the community gave attention, taught, and sometimes hit.

The second pattern: "As best one's economic capacity", the caregivers reflected the view that they had taken care of as much as possible, due to limitations of economic status, and giving less time and attention.

The third pattern: "Caring for miserable", to raise children that the caregivers face their own problems until neglecting children scold and hit the child regularly in the views of the profession.

Thus, problems affecting a child reared, the rural parenting style can affect everything. It's important to ensure the parenting style is supporting healthy growth and development. The effects of villagers' lifestyles have made sense for the raising, abusing, and neglecting children in this village, significantly.

1. Grandparents age still have to earn money to raise them. Having to work on a farm, work all day, in the evening, have to withdraw regularly. Villagers without land weaving, the grandparents must raise a grandchild for his/her young parents to work for making money.

2. Most children were born from parents in school age. They were having sex in various places whereas being a new mother. These children were born under the care of their grandparents. Because 
they had to leave school to find work during they have to young, ready to divorce and go to have a new family, traditionally.

3. The children's lifestyles; primary educational school, children are also riding bicycles, play with friends, stop learning on weekend for playing games at the computer shops. Playing cards during school holidays for making money to buy candy and have fun are the tradition.

4. At the grade level of lower secondary education: they have spent time riding a motorcycle, traveling outside the school with friends of different sexes, began to have a relationship between sexes, some girls became themselves to mothers of their study at the grade 8th level (age of 14-15 years old). While those someone who didn't have a child, they will enter to study at the upper secondary education, or studying for a career or the vocational level at vocational level. However, they have spent time having sexes, continually.

5. Upper educational school age, vocational education, vocational certificate or degree is going to drink alcohol according to merit work. Drunk and face each other for fighting). There are too many boy/girlfriends to belly resigning from the school, living independently about having unique sex, and their childbirth, normally.

6. After some girls have a status as pregnancy, they have to leave out from school to give birth. The need for parents to manage marriage for them who have too young, occupation or job doesn't ready to do. They only gave the burden of raising their children to grandparents. They would spend time sleeping, drinking, traveling, gambling, having sex with a new partner. Not raising children, abusing, and neglecting their child both physically and mentally. Thus, they fled home, travel to work in the capital or the big cities, leave all burdens with grandparents who have to take care of their grandchildren. Sexual activity in general is associated with various risks, which can be reduced with the availability and use of a condom or adopting other safe sex practices. Contraceptives specifically reduce the chance of pregnancy ${ }^{[26]}$.

Teenage pregnancy in Thailand is a major challenge to more than 100,000 girls each year. The unintended pregnancy impedes the potentials many young girls tend to reach in their life. In addition to that, they have to face social stigma and bias attitudes on sexuality in Thailand. This reflects gender inequality in society ${ }^{[27] .}$

\section{ACKNOWLEDGMENT}

This research was partially supported by the National Research University Project, Khon Kaen University, and the National Research Council of Thailand, the project research No. KKU-038/2556 Project in three academic years, Project research number as 021-2556, Project code EXP-01-10- 2014

\section{REFERENCES}

1. A.Mongkolchati A. Prevalence and incidence of child stunting from birth to two years of life in Thai children: based on the Prospective Cohort Study of Thai Children (PCTC). Journal of the Medical Association of Thailand, 2013, 93(12): 1368-78.

2. The National Child Health Development Institute. Annual report 2017: National Child Health Development Institute. Department of Health, Ministry of Public Health, 2017.

3. Howes C. Patterns of friendship. Child Development, 2013, 54(4); 1041-1053. 
4. First Thinks First Investing in early childhood, 2018. Retrieved https://www.firstthingsfirst.org/earlychildhood-matters/investing-in-early-childhood/

5. R. Eibach \&M.S.Steven, The myth of joyful parenthood. Association for Psychological Science. (2017). Retrieved https://www.psychologicalscience.org/news/were-only-human/themyth-of-joyful-parenthood.html

6. A. Capetta, Popular in social development, 2016, Retrieved from https://www.parents.com/kids/development/social/raise-well-rounded-kids/

7. C. Dweck, Applaud and praise efforts: 7 ways to raise a well-rounded kid. Parents, Stanford University. Retrieved https://www.parents.com/kids/development/social/raise-well-roundedkids/TH,2016

8. The Nation. More grandparents playing mum and dad, Retrieved on 18 March 2018 from https://www.pressreader.com,2018

9. N. Phuaphongsakorn N. Free trade agreement: impact in Thailand. Thai Laws. Thailand Research and Development Institute (TDRI).2018, Retrieved http://www.thailaws. Com/law/e_laws/freetrade/ImpactFTAinThailand.pdf

10. Tasty Thailand. Thai family values and how they're different from western ones, 2018. Retrievedhttps://tastythailand.com/thai-family-values-and-how-theyre-different-from-western -ones/

11. S. Bunyarit, Thailand adolescent birth rate: Trends and related indicators. Thai Journal of Obstetrics and Gynaecology, 2014, 22, 15-21.

12. Ministry of Labor. MOL committee meets on workforce skills development, 2019, Retrieved from http://www.mol.go.th/en/anonymouse/homeFriend ,2019

13. Department of Local Administration. Public participation in managing and monitoring the implementation of local administrative organizations, 2018. Retrieved from http://www.dla.go.th/en/index.jsp

14. Population and Social Research Institute. Population of Thailand, 2019. Population Substances. Mahidol University Press 2019.

15. Miller BA., Byrnes HF, Cupp PK, et al. Thai parenting practices, family rituals and risky adolescent behaviors: Alcohol use, cigarette use and delinquency. International Journal of Child Adolescent Health, 2014, 4(4); 367-378.

16. World Health Organization (WHO). International society for prevention of child abuse and neglect: Violence against children, 2016,Retrieved https://www.who.int/healthtopics/violence-against-children\#tab=tab_1

17. UNICEF. Child protection: No child should live in fear, 2017), Retrieved from https://www.unicef.org/thailand/what-we-do/child-protectionPatsinghasane

18. D. Theoklitou, N. Kabitsis \&A. Kabitsi, Physical and emotional abuse of primary school children by teachers. Child Abuse Neglect, 2016, 36 (1); 64-70

19. W.S.Barnett, C.R.Belfield, Early childhood development and social mobility. The Future of Children, special issue: Opportunity in America. Princeton University, 2016, 16 (2); 73-98. 
20. R. Chotchaisathit, Child protection in Thailand: Towards an improved system. Doctoral Thesis, Doctor of Philosophy of Charles Sturt University, Australia, 2014,

21. W. Fongkaew, Gender socialization and female sexuality in Northern Thailand coming of age in South and Southeast Asia: Youth, courtship and sexuality. Nordic Institute of Asian Studies, Copenhagen, 2015, 145-164.

22. UNICEF Thailand. Adolescent situation analysis in Thailand, 2018, Retrieved https://www.unicef.org/thailand/sites/unicef.org.thailand/files/2018-08/adolescent-situationanalysis-thailand-en.pdf

23. The Government Gazette International of Thailand. Act for prevention and solution of the adolescent pregnancy problem, B.E. 2559. Published in the Government Gazette, 2016, 113, 30 a, Page 1, dated 31st March B.E. 2559.

24. D. Kirby, Sex Education: Access and impact on sexual behavior of young people. PowerPoint presentation, ETR Associates, 2012.

25. UNFPA Thailand. Teenage pregnancy and culture on sexuality in Thailand,2017, Retrieved from https://thailand.unfpa.org/en/node/15266

26. Asia Foundation and International Labour Organization. Migrant and child labor in Thailand's shrimp and other seafood supply chains, Bangkok, 2015.

27. H.D.Adams \&S.Sukbunpant, The comparison of special education between Thailand and the United States: Inclusion and support for children with autism spectrum disorder. International Journal of Special Education, 2016, 28, 1; 120-134.

\section{* Corresponding Author: Jirawon Tanwattanakul}

${ }^{1}$ Department of Child Health Nursing, Faculty of Nursing, Khon Kaen University, Khon Kaen Province, Thailand

Date of publication on line 03.09.2020 